\title{
An Integrated Pedagogical Approach for Distance Learning Courses: Curriculum, ICT and Management
}

\author{
Joberto S. B. Martins and Teresinha Quadros \\ Salvador University (UNIFACS), Distance Learning Research Group \\ (NUPPEAD), Rua dos Colibris, 18, 41340 - 410 Salvador, Brazil \\ \{joberto,t.quadros\}@unifacs.br \\ WWW home page: http://www.nuppead.unifacs.br
}

\begin{abstract}
Distance learning courses need intensive planning that, in turn, requires the integration of knowledge and expertise in different areas and levels such as curriculum, ICTs and course management. This paper presents an integrated approach for distance learning course planning that derives from pedagogical research the basic directives to integrate the process variables such as curriculum, ICT options and management. It is argued that distance learning projects always have some research activity involved, since the operation model construction always requires the identification of course characteristics and specificities in order to face the challenges imposed by this teaching method and take advantage of ICT technologies in a specific socioeconomical context. In practical terms, course implementation is focused on pedagogical-driven decisions based on a flexible curriculum model suitable for different implementation scenarios and course characteristics. The integrated approach has been used in various high capillary courses (humanities, mathematics, others) with limited ICT resources.
\end{abstract}

\section{Introduction}

Distance learning pedagogical models have revealed themselves as a valuable teaching approach for attending geographically dispersed mass educational demands, even when located in remote regions where face-to-face (F2F) educational services are not frequently available and ICT resources are scarce or eventually unavailable $[1,3]$. Distance learning courses have faced serious challenges with respect to the adopted pedagogical model and ICT options when their target is focused on large audiences with diversified demands and high capillarity. 
It is argued in this paper that for the definition of a flexible pedagogical model adapted to distance learning it is essential to consider the requirements of the distance learning methods with respect to face-to-face ones. Also, the pedagogical model and the technological options adopted have to be adjusted, eventually case by case, to the specificities of the target audience and specific course characteristics. With respect to course implementation and operation, the approach adopted should additionally be integrated in terms of curriculum, ICTs and management.

In order to illustrate these principles a specific model will be presented and discussed for the pedagogical approach developed and adopted by University Salvador - Unifacs that is intended mainly for graduate and post-graduate courses in areas such as humanities, engineering and computer science. The discussed model was worked out as a research activity developed prior to course implementation by a multidisciplinary team at NUPPEAD (Distance Learning Research Group) and, in brief, looks to provide a set of guiding principles for groups dealing with the problem of implementing distance learning courses in diversified implementation scenarios.

\section{The integrated pedagogical approach concept and principles}

The integrated pedagogical approach concept represents a reference term integrating the various project planning dimensions and its implementation dynamics such as the curriculum model, the learning management approach, the tutoring system, the technological infrastructure, the logistics and the assessment and evaluation methods and procedures (Figure 1). Each one of these dimensions has to be in accordance with the defined institutional pedagogical principles, and beyond that has to overcome the distance learning specific limitations.

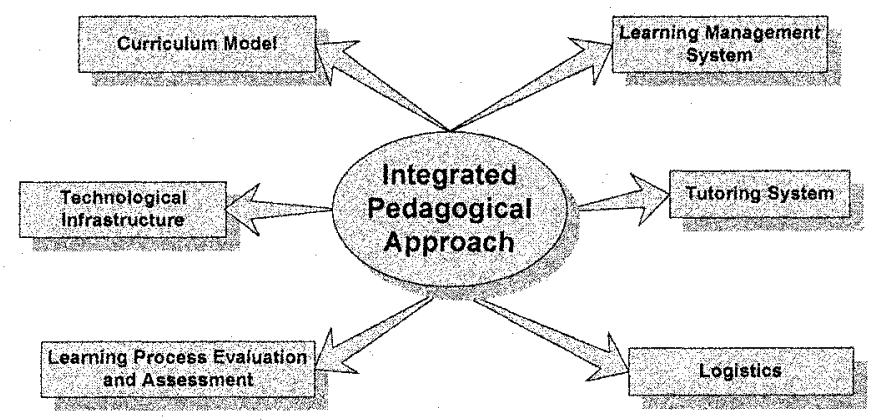

Figure 8. Integrated Pedagogical Approach

In brief, the integrated approach proposed is based on a set of general basic principles such as: collaborative work, interdisciplinary methods, autonomous learning, and meaningful learning $[2,3,4]$. 


\section{Curriculum model - learning core units, thematic matrixes, flow and module}

The curriculum model proposed for the integrated pedagogical approach is structured in various articulated units focusing on providing the target course profile. The units are "Learning Core Units", "Thematic Matrix", "Flow" and "Module" (Figure 2) and, in brief, they try to guarantee the interdisciplinary methods and collaborative work.

\begin{tabular}{|c|c|c|c|c|c|c|}
\hline Matrix 01 & Matrix 02 & Matrix 03 & Matrix 04 & $\begin{array}{l}\text { Integration } \\
\text { Matrix }\end{array}$ & Flow & \\
\hline Moduk 01 & Module ot & & Module ol & Module 01 & Flow 01 & \multirow{2}{*}{ Coreol } \\
\hline Module 02 & Modulo oz & & Module 02 & Módute o2 & How 02 & \\
\hline \multirow[t]{5}{*}{ Modulte 03} & Module o3 & Module o1 & & Module os & flow 03 & \multirow{3}{*}{ Core 02} \\
\hline & Module 04 & Module 02 & & Module 04 & Flow 04 & \\
\hline & \% & Module 03 & Module 03 & Module 05 & Flow os & \\
\hline & & Module o4 & Module 04 & Module 06 & Flow 06 & \multirow{2}{*}{ Core 03} \\
\hline & & & & Module or & Flow 07 & \\
\hline
\end{tabular}

Figure 2. Curriculum Model - Core, Matrix, Flow and Modules

The learning core units correspond to the units defining competences and skills to be developed through the different steps of the professional formation. Each defined learning core unit is a curricular unit equivalent to course main areas which represent specific moments of the course and steps in the professional formation process. The learning core units are composed of either part of or entire "matrix units" and define skills and competences which are to be stimulated and developed in all moments of the educational process. The core has its own objectives and proposes interdisciplinary methods both in horizontal (time frame/ flow) and vertical (curricular completion) planes.

Thematic matrices are curricular units expressed vertically and composed of sets of disciplines which define specific curriculum thematic fields. Matrices articulate disciplines and related contents to knowledge areas. Each matrix has its own interdisciplinary objective and content that effectively articulates its disciplines and objectives. Distance learning curricula are composed of matrices whose number and time duration are defined according to the specificities and duration of the distance learning course.

The integrating matrix (Figure 2) is an important element of the pedagogical approach and is present for the entire course execution period. Its function, as suggested by the name, is to integrate through project development student learning experiences throughout the various flows previewed for the course.

Flows are temporal units in the context of distance learning courses but have no relation to the traditional temporal units adopted by face-to-face courses (periods, semesters, others). Flows in this integrated pedagogical approach correspond to the offering of thematic modules in pre-defined time frames. Flow duration is defined 
according the complexity of their discipline contents and, typically, provide a realizable execution time frame.

Modules are the basic components of the matrices and are composed of the set of course contents and corresponding disciplines they congregate. In the curriculum model adopted in the integrated pedagogical approach each module integrates a set of course contents which in classical face-to-face curricula would be dispersed in independent disciplines.

In brief, the proposed pedagogical approach is composed of curricular units which operate in an integrated fashion in order to promote the articulation between course contents, competences and skills.

\section{ICT options and course management}

The information and communications technology (ICT) options to be adopted in the proposed pedagogical approach follow the basic principle of using multiple technological resources either isolated or in conjunction. The effective choices are made according to course objectives, audience profile and local infrastructure facilities available. In addition, the course logistics are adapted to the socioeconomics of the target public and region and, as such, the technological infrastructure available has to be taken into account $[3,4]$.

Course management is a fundamental aspect of the integrated pedagogical approach, which proposes a new management model structure with a Course Coordination and Mediation element, a Technical Coordination element and a Matrix Coordination element (Figure 3).

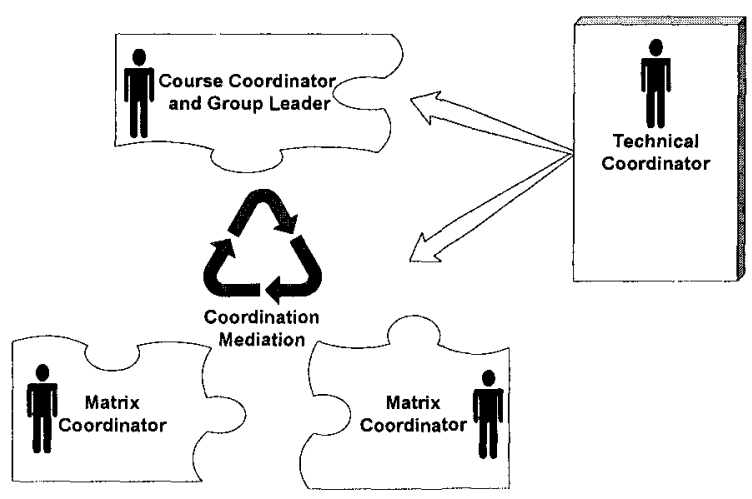

Figure 3. Course Management Actors

The course coordinator, as the name suggests, is the mainelement responsible for the general coordination of the educational process and, beyond that, acts collaboratively in a more general structure where other specific coordination activities are present. In this structure the technical coordinator is a distance learning specialist whose main responsibility is to promote the interchange of expertise 
among the various courses implemented according the integrated pedagogical approach. The matrix coordinators are responsible for the multidisciplinary course content integration under course coordinator supervision and mediation. Each matrix has its own matrix coordinator working, typically, part time or, optionally, two thematic matrixes are conducted by a single matrix coordinator working, typically, full time.

\section{The integrated pedagogical approach - experimental cases and conclusion}

The integrated pedagogical approach has been applied to the following distance learning undergraduate courses at Salvador University: Pedagogy Course (2.900 hours) - undergraduate course - number of students: 3.000; Agricultural Business Management (1890 hours) - undergraduate course - number of students: 160; Retail Management (1890 hours) - undergraduate course - number of students: 160; Portuguese and English Language (2.940 hours) - undergraduate course - number of students: 500; Mathematics (2.900 hours) - undergraduate course - number of students: 700

The implemented courses had their curricula defined according to the basic institutional pedagogical principles (collaborative work, interdisciplinary methods, autonomous and meaningful learning). The different course dimensions (curriculum, tutoring, technological infrastructure, logistics, assessment) have been addressed in an integrated planning process, and the technological options have adopted multiple media and multiple communication resources principles.

\section{References}

1. Kendall, Mike; Weert, Tom Wan. (2005) Growing Importance of Lifelong Learning with ICT. In: IFIP World Conference on Computers in Education - WCCE 2005. Cape Town.

2. Martins, Joberto S. B. et alli. (2002) Interdisciplinary and Flexible Curricula Practices in Electric and Telecommunications Engineering - A Case Study. IFIP Working Group 3.2 Conference - Informatics and ICT in Higher Education - ICTEM 2002, Florianópolis.

3. Martins, Joberto S. B. and Quadros, T. (2004) Experiences and Practices in Modeling Distance Learning Curricula for Capillary Approaches and Limited ICT Resource Scenarios. In: IFIP Working Group 3.2 \& 3.4 Workshop - Information and Communication Technologies (ICT) and Real-life Learning, Melbourne, Springer, pp. 55-66.

4. Martins, Joberto S B and Marback, G. (2005) Evaluating by Experience the Role of Teachers and Tutors in Distance Learning Education. In: IFIP World Conference on Computers in Education - WCCE 2005. Cape Town. 